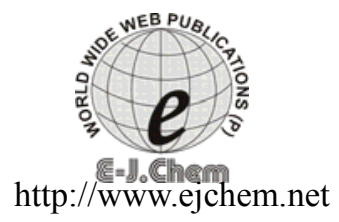

\title{
Kinetic Determination of Paracetamol using a Novel Belousov-Zhabotinskii Oscillating System Catalyzed by a Tetraazamacrocyclic Complex
}

\author{
GANG HU ${ }^{\S *}$, QIN WANG $^{\S}, \mathrm{MIN} \mathrm{MENG}^{\S}$, MING YING LU ${ }^{\S}$, FU SHENG ZHAO ${ }^{\S}$ AND \\ LIN HU \\ ${ }^{\S}$ Department of Chemistry, Anhui University, No. 3 Feixi Road, Hefei, Anhui, 230039, \\ China \\ Institute of Applied Chemistry, East China Jiaotong University, Nanchang 330013, China \\ hugang@ustc.edu
}

Received 20 September 2011; Accepted 08 November 2011

\begin{abstract}
A new analytical method for determination of paracetamol is proposed. This method is based on a novel B-Z oscillating system, which involves a Tetraazamacrocyclic Complex $[\mathrm{CuL}]\left(\mathrm{ClO}_{4}\right)_{2}$ as catalyst and malic acid as the substrate. The ligand $\mathrm{L}$ in the complex is 5,7,7,12,14,14-hexamethyi-1,4,8,11-tetraazacyclotetradeca-4,11-diene. By perturbation mount of paracetamol on the B-Z system, there is a linear relationship between the changes in the oscillation amplitude and the logarithm of paracetamol concentration in the range $5 \times 10^{-7}$ to $2 \times 10^{-4} \mathrm{M}$, with a correlation coefficient of 0.99743 . The effects of influential variables, such as the concentration of reaction components, temperature and on the determinations were studied. The probable mechanism involving the perturbation of paracetamol on the oscillating chemical system was also discussed.
\end{abstract}

Keywords: Determination, Paracetamol, Oscillating chemical reaction, Tetraazamacrocyclic complex.

\section{Introduction}

Chemical oscillating reaction is one of a class of reactions that serve as a classical example of non-equilibrium thermodynamic, showing periodic changes in some intermediates over time $^{1}$. Because oscillating reaction is far from equilibrium, it provides not only an interesting chemical model of non-equilibrium phenomena but theoretical interests for mathematical models as well. Current research in chemical oscillation field has covered design of chemical oscillators, dynamic features and applications of chemical oscillation to the other fields.

Using oscillating reaction in the analytical field can be traced back to 1978 , when Tichonova et al. ${ }^{2}$ chose a Belousov-Zhabotinskii reaction (B-Z) for quantitative analysis of $\mathrm{Ru}(\amalg)$. Some other chemical oscillators, like Briggs-Rauscher (BR) reaction ${ }^{3-6}$, 
Bray-Liebhafsky (BL) reaction ${ }^{7-12}$ and $\mathrm{H}_{2} \mathrm{O}_{2}-\mathrm{NaSCN}-\mathrm{CuSO}_{4}$ system ${ }^{13-15}$ have also been used as matrixes for analytical purpose. However, the disadvantages of B-R reaction are that its oscillating profile is unstable and that it has a short lifetime and poor reproducibility. B-L system is very complicated, and sometime this character limited its use in quantitative analysis only being in a stable non-equilibrium stationary state close to the bifurcation point between stable and oscillatory state ${ }^{16} \cdot \mathrm{H}_{2} \mathrm{O}_{2}-\mathrm{NaSCN}-\mathrm{CuSO}_{4}$ system is usually accomplished by using a continuous flow stirred-tank reactor (CSTR). Although continuous flow stirred-tank reactor can provide a stable oscillatory profile, it is more complicated system which requires experimental skills and which consumes a great mount of reagents. Compared with the Briggs-Rauscher reaction, Bray-Liebhafsky reaction, and $\mathrm{H}_{2} \mathrm{O}_{2}-\mathrm{NaSCN}-\mathrm{CuSO}_{4}$ system, Belousov-Zhabotinskii reaction has some advantages. For example: oscillating profile of Belousov-Zhabotinskii reaction is relatively stabler, and that its lifetime is correspondingly longer. The features of $\mathrm{B}-\mathrm{Z}$ reaction benefit analytical determination. Moreover, Belousov-Zhabotinskii reaction ${ }^{17}$ is more thoroughly studied chemical oscillator, and its mechanism is better understood than any other oscillators.

Paracetamol is one of the most favorite anti-inflammatory antipyretic analgesics that is readily absorbed after administration and has few side effects and little toxicity when used in recommended dose. If someone takes excessive paracetamol, the accumulation of toxic metabolites may cause severe and sometimes fatal hepatotoxicity and nephrotoxicity ${ }^{18}$. Hence, the accurate determination of paracetamol in pharmaceutical preparations is very important. For its measurement, many methods have been applied, such as fluorometry ${ }^{19}$, nuclear magnetic resonance-mass spectrometry ${ }^{20}$, electrochemical method ${ }^{21}$, liquid chromatography $^{22,23}$, chemiluminescence ${ }^{24}$, capillary column gas chromatography ${ }^{25}$, spectrophotometric method ${ }^{18,26}$, sequential injection chromatographic ${ }^{27}$, capillary electrophoresis ${ }^{28}$ and derivative spectrophotometry ${ }^{29}$.

This article reports a novel and convenient method for the determination of paracetamol based on its perturbation effect on $[\mathrm{CuL}]\left(\mathrm{ClO}_{4}\right)_{2}$-catalyzed $\mathrm{B}-\mathrm{Z}$ oscillating reaction $\left(\mathrm{NaBrO}_{3}-\mathrm{H}_{2} \mathrm{SO}_{4}-\right.$ malic acid- $\left.[\mathrm{CuL}]\left(\mathrm{ClO}_{4}\right)_{2}\right)$. The ligand $\mathrm{L}$ in the mocrocyclic complex is $5,7,7,12,14,14$-hexamethyi-1,4,8, 11-teteaazacyclotetradeca-4,11-diene. The change in oscillation amplitude $(\Delta \mathrm{A})$ is linearly proportional to the logarithm of the concentration of paracetamol in the range $5 \times 10^{-7}$ to $2 \times 10^{-4} \mathrm{M}$. Compared with the above methods, this methodology uses very simple instruments and common, inexpensive reagents, and that it has higher sensitivity and reproducibility. This method suggested by our group has been already applied to determine to pyrogallol $l^{30}$, catechol ${ }^{31}$, alizarin red $\mathrm{S}^{32}$ and calcium pantothenate ${ }^{33}$.

Although paracetamol has been tested by using $\mathrm{H}_{2} \mathrm{O}_{2}-\mathrm{NaSCN}-\mathrm{CuSO}_{4}$ oscillating system as matrix, the liner range of this method is from 0.5 to $6 \mu \mathrm{M}^{34}$. In our approach, it can be seen that the linear range of our method is from $5 \times 10^{-7}$ to $2 \times 10^{-4} \mathrm{M}$, which is different from above data.

\section{Experimental}

\subsection{Reagents}

All chemicals used to create the $\mathrm{B}-\mathrm{Z}$ oscillating system, such as $\mathrm{NaBrO}_{3}, \mathrm{H}_{2} \mathrm{SO}_{4}$ and malic acid were of analytical - reagent grade and used as received. The catalyst $[\mathrm{CuL}]\left(\mathrm{ClO}_{4}\right)_{2}$ was prepared according to a published procedure ${ }^{35}$. Solutions of $0.5 \mathrm{M} \mathrm{NaBrO}_{3}, 2 \mathrm{M}$ malic acid and $0.0221 \mathrm{M}[\mathrm{CuL}]\left(\mathrm{ClO}_{4}\right)_{2}$ were prepared in $1 \mathrm{M}$ sulfuric acid. Stock solutions of $0.01 \mathrm{M}$ paracetamol were made immediately in water before the experiments. Solutions with lower concentrations were prepared freshly just prior to use. Double distilled water was used in all cases. 


\subsection{Apparatus}

All the oscillating reactions were conducted using a glass container $(50 \mathrm{~mL})$ with a Model 79-3 magnetic stirrer (Jiangsu, China) and a thermostat. A type 213 platinum electrode was used as the working electrode, and a type 217 saturated calomel electrode connected through a salt bridge containing $1 \mathrm{M} \mathrm{Na}_{2} \mathrm{SO}_{4}$ as the reference electrode. A type PHS-25B digital voltmeter (Shanghai, China) connected with a model XWTD-264 y-t recorder (Shanghai, China) was used to record the potential changes.

\subsection{Procedures}

\subsubsection{Potentiometric Measurements}

The catalyst $[\mathrm{CuL}]\left(\mathrm{ClO}_{4}\right)_{2}$ was prepared by a known technique ${ }^{35}$ and identified by its IR spectra and elemental analysis. To the glass at $20 \pm 0.5^{\circ} \mathrm{C}$, solutions were added in the following sequence: $1.5 \mathrm{~mL}$ of $0.5 \mathrm{M} \mathrm{NaBrO}_{3}$ solution, $29 \mathrm{~mL}$ of $1 \mathrm{M} \mathrm{H}_{2} \mathrm{SO}_{4}$ solution, $4 \mathrm{~mL}$ of $2 \mathrm{M}$ malic acid solution, and $5.5 \mathrm{~mL}$ of $0.0221 \mathrm{M}[\mathrm{CuL}]\left(\mathrm{ClO}_{4}\right)_{2}$ solution up to a final volume of $40 \mathrm{~mL}$. The mixture was homogenized by continuous magnetic stirring at a rate of $500 \mathrm{rpm}$. The working electrode and reference electrode were immersed in the reaction mixture and data acquired by the $y$-t recorder was collected. After the oscillating system was run for six cycles, and then variable amounts of paracetamol were added to the reaction system at the bottom of the potentiometric cycle with a trace injector, to perform the perturbation experiments. The changes in oscillating amplitude $\Delta \mathrm{A}\left(\Delta \mathrm{A}=\mathrm{A}-\mathrm{A}_{0}\right.$, where $\mathrm{A}_{0}$ and $\mathrm{A}$ are the amplitude before and after the injection, respectively) were used as parameter to determination of paracetamol.

\subsubsection{Cyclic Voltammetry}

In order to gain more information about the mechanism of the interaction of paracetamol on the macrocyclic complex $[\mathrm{CuL}]\left(\mathrm{ClO}_{4}\right)_{2}$-catalyzed $\mathrm{B}-\mathrm{Z}$ type oscillation, cyclic voltammary experiments were performed to monitor the species, which reacted with paracetamol.

\section{Results and Discussion}

\section{$3.1[\mathrm{CuL}]\left(\mathrm{ClO}_{4}\right)_{2}$-catalyed B-Z Oscillating Reaction}

In a closed system, $[\mathrm{CuL}]\left(\mathrm{ClO}_{4}\right)_{2}$-catalyed $\mathrm{B}-\mathrm{Z}$ oscillating system emerges a very shot induction period, followed by an oscillatory stage. The color of the solution alternates between red and orange (because the concentrations of $[\mathrm{CuL}]^{2+}$ and $[\mathrm{CuL}]^{3+}$ alternated during oscillating) with an oscillation period of 55 seconds at the optimum conditions. The typical oscillation can last over 2 hour. Ultimately, with the concentrations of the reactants decreasing continuously during the reaction process, the oscillator would cease. However, a first 20 minutes, the profile of the $[\mathrm{CuL}]\left(\mathrm{ClO}_{4}\right)_{2}$-catalyed system is that it has consistent waveforms, with approximately constant oscillation period and constant amplitude, which may favor for determination of analytes by their perturbation effect on amplitude.

\subsection{Results}

Perturbing the oscillating system by injection a microvolume of sample containing a given amount of paracetamol caused a change in the oscillation amplitude that was quantitatively related to the analyte concentration in the injected sample. Fig.1a and Fig.1b show the typical oscillation profiles obtained for the absence and presence of paracetamol perturbation under the above-described experimental conditions. When the concentration of paracetamol is over the range $5 \times 10^{-7}$ to $2 \times 10^{-4} \mathrm{M}$ (Fig. 2), the changes in oscillation amplitude $(\Delta \mathrm{A})$ obtained were linearly proportional to the logarithm of the paracetamol concentration. The following linear relationship was obtained: 


$$
\Delta \mathrm{A}=538.21809+83.7932 \log [\text { paracetamol }](\mathrm{n}=13)
$$
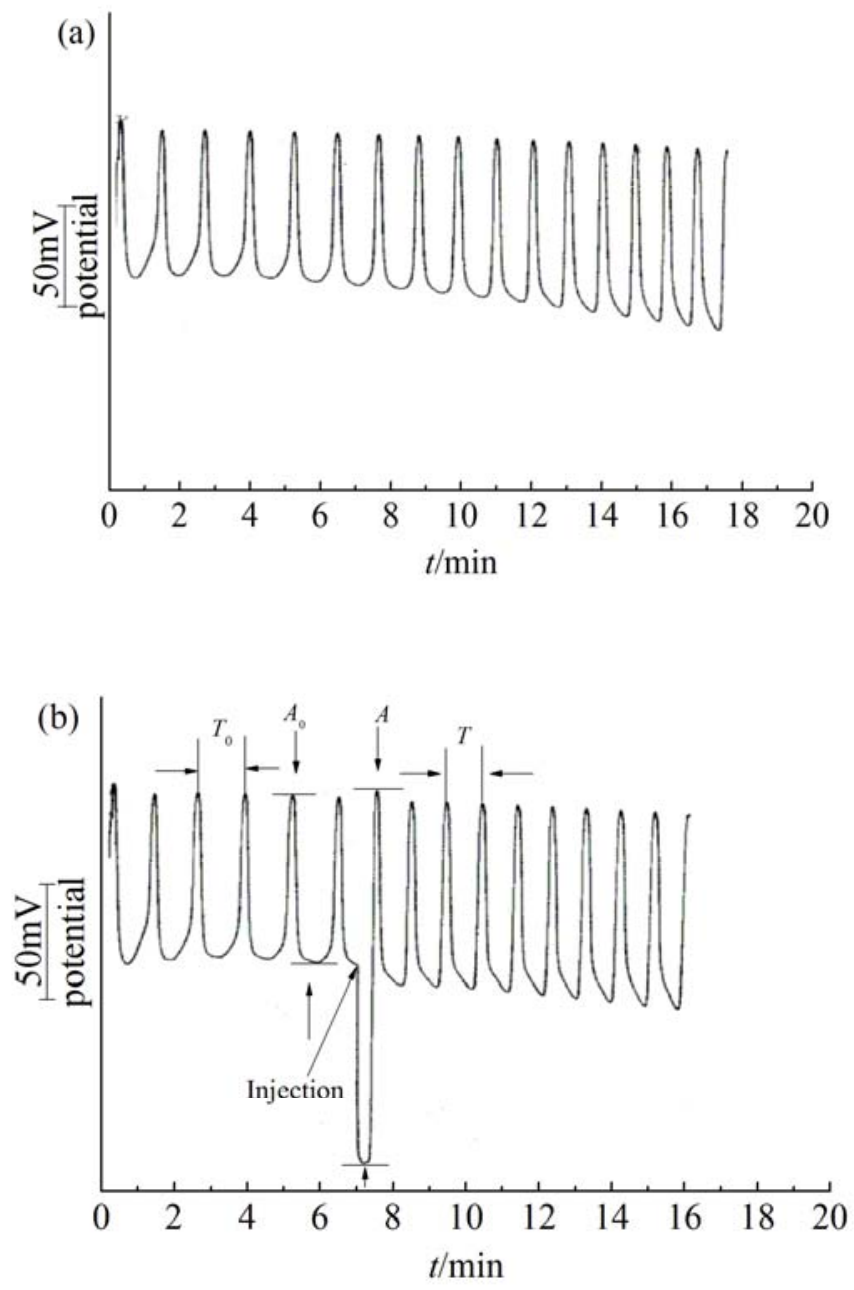

Figure 1 Typical oscillating profiles for the proposed oscillation system in the absence and presence of $1.25 \times 10^{-5} \mathrm{M}$ paracetamol perturbation using platinum electrode: (a) $[$ paracetamol $]=0.000 \mathrm{M}\left(\right.$ b) $[$ paracetamol $]=1.88 \times 10^{-5} \mathrm{M}$. Common conditions: $\left[\mathrm{NaBrO}_{3}\right]=$ $1.875 \times 10^{-2} \mathrm{M}$; [malic acid] $\left.=0.20 \mathrm{M}:\left[\mathrm{H}_{2} \mathrm{SO}_{4}\right]=1.0 \mathrm{M} ;[\mathrm{CuL}]\left(\mathrm{ClO}_{4}\right)_{2}\right]=3.04 \times 10^{-3} \mathrm{M}$.

The behavior of the oscillating systems is highly vulnerable in the presence of foreign species in the reaction medium. Consequently, we investigated the effects of some common ions and strong reductive species. Under the optimum conditions, the determination of $1.25 \times 10^{-5} \mathrm{M}$ paracetamol was injected into the oscillating system and the results of influence of foreign ions and species obtained were shown in Table 1. It can be seen that halideion, $\mathrm{Ag}^{+}, \mathrm{Fe}^{2+}$ and $\mathrm{NO}_{2}^{-}$had a strong influence on determination of paracemol. Therefore these reducible ions should be avoided in determination of paracetamol. 
Table 1 Influence of foreign ions and species on the determination of $1.25 \times 10^{-5} \mathrm{M}$ paracetamol.

\begin{tabular}{lc}
\hline Foreign ions and species & Tolerated ratio \\
\hline $\mathrm{Na}^{+}, \mathrm{Li}^{+}, \mathrm{Cu}^{2+}, \mathrm{Zn}^{2+}, \mathrm{NH}_{4}^{+}$ & 1000 \\
$\mathrm{Mn}^{2+}$ & 100 \\
$\mathrm{Mg}^{2+}, \mathrm{Co}^{2+}$ & 50 \\
$\mathrm{Fe}(\mathrm{CN})_{6}^{-}, \mathrm{Cl}^{-}$ & 10 \\
$\mathrm{~F}^{-}, \mathrm{H}_{2} \mathrm{PO}_{4}^{-}$ & 5 \\
$\mathrm{Br}^{-}$ & 1 \\
$\mathrm{I}^{-}, \mathrm{Ag}^{+}, \mathrm{Fe}^{2+}, \mathrm{NO}_{2}^{-}$ & 0.1 \\
\hline
\end{tabular}

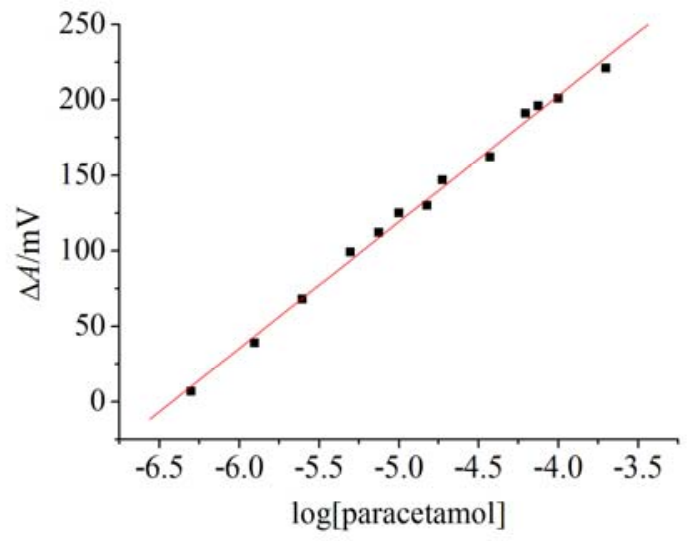

Figure 2 Calibration curve of the increase in amplitude vs. the logarithm of [paracetamol] in the range $5 \times 10^{-7}$ to $2 \times 10^{-4} \mathrm{M}$. Conditions: $\left[\mathrm{NaBrO}_{3}\right]=1.875 \times 10^{-2} \mathrm{M}$; [malic acid] $=0.20 \mathrm{M}$; $\left[\mathrm{H}_{2} \mathrm{SO}_{4}\right]=1.0 \mathrm{M} ;\left[[\mathrm{CuL}]\left(\mathrm{ClO}_{4}\right)_{2}\right]=3.04 \times 10^{-3} \mathrm{M}$.

\subsection{Influence of Experimental Variables}

To ensure the maximum possible sensitivity and accuracy in the determination of paracetamol, we investigated that changing each variable in turn while keeping all other constant optimized the oscillating system. The effects of the variable influence of the behavior of the oscillating system were adequately studied in absence and presence of paracetamol perturbations. The measured parameters used for this purpose were the change of the oscillation amplitude $\Delta \mathrm{A}$ and the change of the period $\Delta \mathrm{T},\left(\Delta \mathrm{T}=\mathrm{T}-\mathrm{T}_{0}\right.$, where $\mathrm{T}_{0}$ and $\mathrm{T}$ are the periods of oscillating profiles before and after injecting paracetamol, respectively).

$\mathrm{B}-\mathrm{Z}$ oscillating system was usually carried out in acidic medium. If the concentration of sulfuric acid used were too high or low, the oscillating system would be unstable. From the experimental results, it was found that the system was stable when the concentration of sulfuric acid was in the range from 0.70 to $1.375 \mathrm{M}$ (Fig.3a). When sulfuric acid concentration is lower than $0.70 \mathrm{M}$, the oscillating only last for some short periods and it ceased finally. When the sulfuric acid concentration is too high, the oscillation appeared marked drift. A $1 \mathrm{M}$ sulfuric acid concentration was chosen as optimal since it caused the system to oscillating highly uniformly prior to the perturbation and responded quite predictably. 

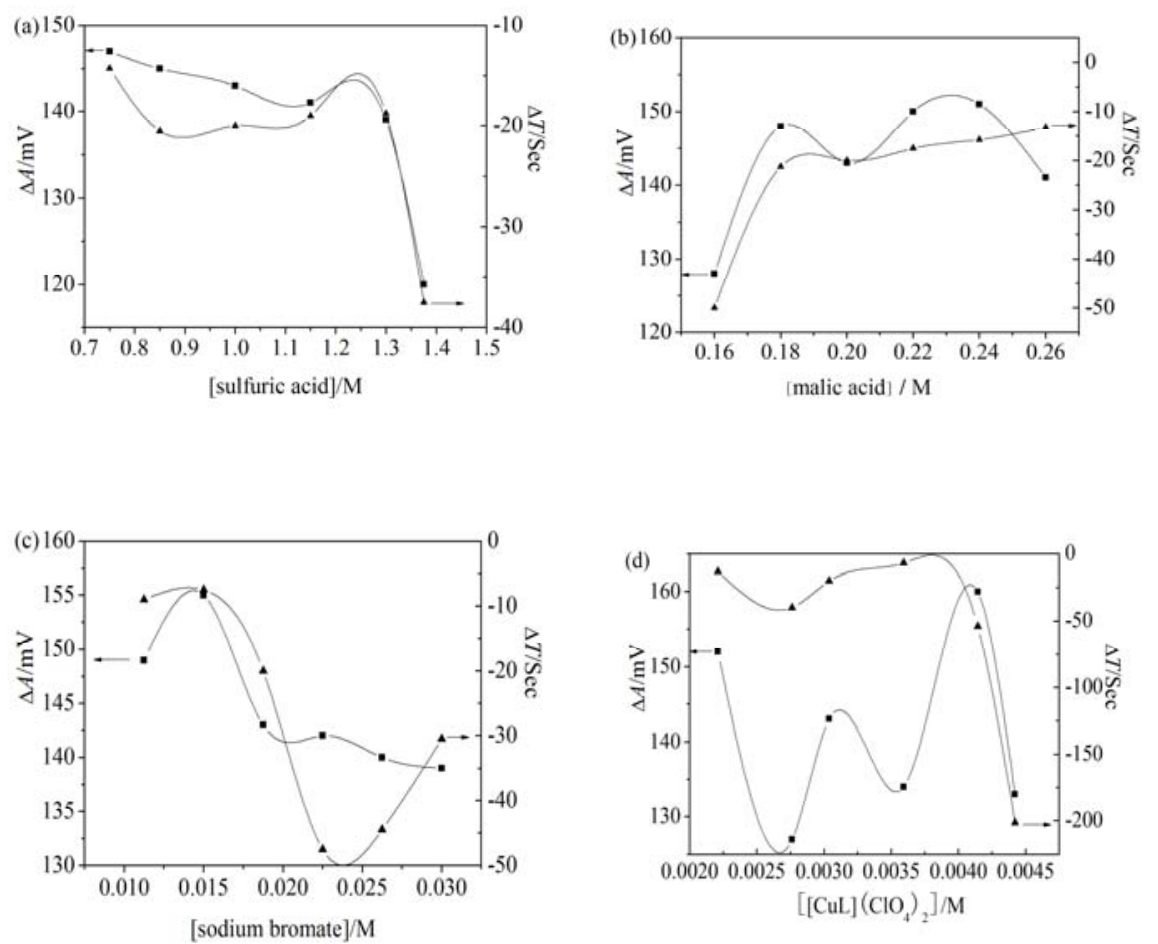

Figure 3 Influence of the concentration of (a) sulfuric acid; (b) malic acid; (c) sodium bromate; (d) $[\mathrm{CuL}]\left(\mathrm{ClO}_{4}\right)_{2}$; on the oscillation system in the presence of $1.88 \times 10^{-5} \mathrm{M}$ paracetamol $(\boldsymbol{\square}$ refers to $\Delta \mathrm{A}$ and $\boldsymbol{\Delta}$ refers to $\Delta \mathrm{T})$ Conditions: (a) $\left[[\mathrm{CuL}]\left(\mathrm{ClO}_{4}\right)_{2}\right]=3.04 \times 10^{-3}$ $\mathrm{M},\left[\mathrm{NaBrO}_{3}\right]=1.875 \times 10^{-2} \mathrm{M},[$ malic acid $]=0.20 \mathrm{M}$; (b) $\left[[\mathrm{CuL}]\left(\mathrm{ClO}_{4}\right)_{2}\right]=3.04 \times 10^{-3} \mathrm{M}$, $\left[\mathrm{NaBrO}_{3}\right]=1.875 \times 10^{-2} \mathrm{M},\left[\mathrm{H}_{2} \mathrm{SO}_{4}\right]=1.0 \mathrm{M}$; (c) $\left[[\mathrm{CuL}]\left(\mathrm{ClO}_{4}\right)_{2}\right]=3.04 \times 10^{-3} \mathrm{M}$, [malic acid] $=0.20 \mathrm{M},\left[\mathrm{H}_{2} \mathrm{SO}_{4}\right]=1.0 \mathrm{M}$; (d) $\left[\mathrm{NaBrO}_{3}\right]=1.875 \times 10^{-2} \mathrm{M}$, [malic acid $]=0.20 \mathrm{M},\left[\mathrm{H}_{2} \mathrm{SO}_{4}\right]$ $=1.0 \mathrm{M}$.

Malic acid is one of the essential substrates in B-Z oscillating system. The effect of malic acid concentration was studied over the range from 0.16 to $0.26 \mathrm{M}$. When the concentration of malic acid is lower than $0.16 \mathrm{M}$, the amplitude of the oscillation increased dramatically after several short oscillation cycles. From Fig. 3b, it found that with increasing malic acid concentration, $\Delta \mathrm{A}$ first went up to a maximum, then went down to a minimum, after that it went up again and went down eventually. $\Delta \mathrm{T}$ increased as the malic acid concentration increased. At the concentration of $0.2 \mathrm{M}$, the better responses were obtained both from changes of oscillating amplitude and period.

The sodium bromate concentration in B-Z oscillating system was changed between 0.01125 and $0.03 \mathrm{M}$. As the concentration was increased, both the $\Delta \mathrm{A}$ and $\Delta \mathrm{T}$ first increased to a maximum, then both them decreased to a minimum, and after that $\Delta \mathrm{A}$ decreased gradually, but $\Delta \mathrm{T}$ increased eventually (Fig. 3c). A concentration of $0.01875 \mathrm{M}$ was finally chosen as a compromise between maximum sensitivity changes of oscillating amplitude and minimum analysis time (change of oscillating period).

The concentration of the catalyst $[\mathrm{CuL}]\left(\mathrm{ClO}_{4}\right)_{2}$ used in the oscillating system was tested from 0.00221 to $0.00442 \mathrm{M}$. It was found that without the perturbation of paracetamol on the oscillating system, it hardly had effect on the oscillation amplitude when 
the concentration of $[\mathrm{CuL}]\left(\mathrm{ClO}_{4}\right)_{2}$ changes. However, the oscillation period increased dramatically with the increase of $[\mathrm{CuL}]\left(\mathrm{ClO}_{4}\right)_{2}$ concentration. The perturbations of paracetamol yield a response that fitted a curve of Fig. 3d. It found that the curve of the changes of oscillating amplitude $(\Delta \mathrm{A})$ first went down and then went up to a maximum, after that it went down and went up again, and at last it went down finally. The changes of oscillating period $(\Delta \mathrm{T})$ decreased to a minimum and then increased gradually to minimum, and after that it decreased suddenly. According to the above three criteria, the value of $3.04 \times 10^{-3} \mathrm{M}$ was selected for the optimum concentration.

\subsection{Mechanism of Action of Paracetamol on the Oscillation System}

The mechanisms of oscillation reaction are rather complex. Often, the oscillation systems consist of many kinetic steps involving several independent variables ${ }^{14}$. Elucidating the nature of the interactions of the analytes with oscillation reactions was no easy task. However, the famous FKN mechanism proposed by Field et al. ${ }^{36}$ is generally accepted. According to $\mathrm{FKN}$ model, the $[\mathrm{CuL}]^{2+}$-catalyzed oscillating system was proposed seven reactions and described three processes ${ }^{30-33,37}$. The overall reactions are as follows.

Process (A):

$$
\begin{aligned}
& \mathrm{BrO}_{3}^{-}+\mathrm{Br}^{-}+2 \mathrm{H}^{+} \rightleftharpoons \mathrm{HOBr}+\mathrm{HBrO}_{2} \\
& \mathrm{HBrO}_{2}+\mathrm{Br}^{-}+\mathrm{H}^{+} \rightleftharpoons 2 \mathrm{HOBr} \\
& \mathrm{HOBr}+\mathrm{Br}^{-}+\mathrm{H}^{+} \rightleftharpoons \mathrm{Br}_{2}+\mathrm{H}_{2} \mathrm{O} \\
& \mathrm{Br}_{2}+\mathrm{HOOCCHOHCH} \mathrm{HOOH}_{2} \mathrm{COH}
\end{aligned}
$$

$$
\mathrm{Br}^{-}+\mathrm{H}^{+}+\mathrm{HOOCCHOHBrCHCOOH}
$$

Process (B):

$$
\begin{aligned}
& \mathrm{BrO}_{3}^{-}+\mathrm{HBrO}_{2}+\mathrm{H}^{+} \rightleftharpoons 2 \mathrm{BrO}_{2} \cdot+\mathrm{H}_{2} \mathrm{O} \\
& \mathrm{BrO}_{2} \cdot+[\mathrm{CuL}]^{2+}+\mathrm{H}^{+} \longrightarrow[\mathrm{CuL}]^{3+}+\mathrm{HBrO}
\end{aligned}
$$

Process (C):

$\mathrm{HOOCCHOHBrCHCOOH}+6[\mathrm{CuL}]^{3+}+3 \mathrm{H}_{2} \mathrm{O} \longrightarrow$

$$
6[\mathrm{CuL}]^{2+}+\mathrm{Br}^{-}+2 \mathrm{HCOOH}+2 \mathrm{CO}_{2}+7 \mathrm{H}^{+}
$$

Process $\mathrm{A}$ and $\mathrm{B}$ are two major processes, which control the oscillating reaction alternately and result in oscillations in the concentration of the intermediate species. When the concentration of bromide ions $\left(\mathrm{Br}^{-}\right)$is high enough, the whole oscillating reactions are dominated by the Process A. At this time, the potential of platinum electrode is located in maximum. With reaction (1)-(3) going, the concentration of bromide ions $\left(\mathrm{Br}^{-}\right)$is gradually 
reduced by reaction (1), which is a rate-controlling step in process A. Reaction (4) is the bromination reaction of malic acid with $\mathrm{Br}_{2}$ in $[\mathrm{CuL}]^{2+}$-catalyzed system, resulting in consuming $\mathrm{Br}^{-}$ion. When the concentration of bromide ion is too small to maintain reaction (1), reaction (5) would occur. After that $[\mathrm{CuL}]^{2+}$ would react with $\mathrm{BrO}_{2}$. which is the production of reaction (5), and at the same time $[\mathrm{CuL}]^{2+}$ is oxide by $\mathrm{BrO}_{2}$. in reaction (6), making $[\mathrm{CuL}]^{2+}$ become $[\mathrm{CuL}]^{3+}$. When the concentration of $[\mathrm{CuL}]^{3+}$ increases massively, reaction (7) will occur to regenerate $\mathrm{Br}^{-}$and it accompany by $[\mathrm{CuL}]^{3+}$ back to $[\mathrm{CuL}]^{2+}$, making process $\mathrm{B}$ auto-change into process $\mathrm{C}$. When the concentration of bromide ions is reached up to a maximum, the next new cycle will begin.

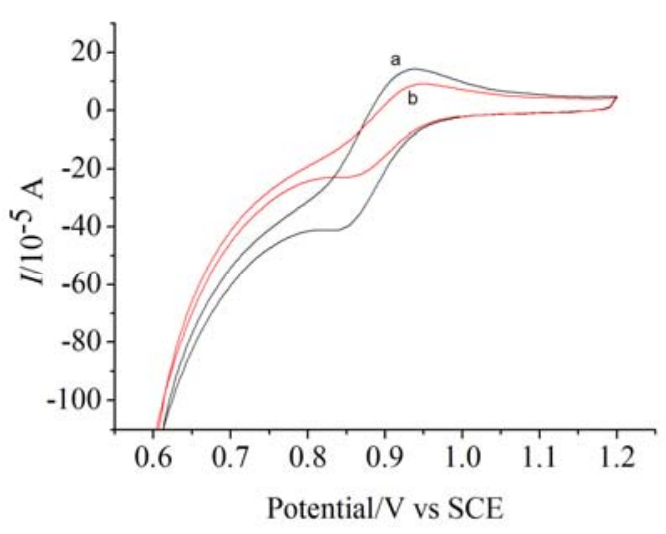

Figure 4 Cyclic voltammograms of the reactions in (a) $\left[\mathrm{NaBrO}_{3}\right]=2.5 \times 10^{-2} \mathrm{M},\left[\mathrm{H}_{2} \mathrm{SO}_{4}\right]=$ $1.0 \mathrm{M}$, [paracetamol] $=0$; (b) $\left[\mathrm{NaBrO}_{3}\right]=2.5 \times 10^{-2} \mathrm{M},\left[\mathrm{H}_{2} \mathrm{SO}_{4}\right]=1.0 \mathrm{M}$, [paracetamol] $=$ $2.5 \times 10^{-5} \mathrm{M}$; scan rate $=100 \mathrm{mV} / \mathrm{s}$.

To clarity which species in the B-Z system reacted with paracetamol, the cyclic voltammetry was applied, in the absence and presence of paracetaol, to the following media: (a) $\mathrm{H}_{2} \mathrm{SO}_{4}+\mathrm{NaBrO}_{3}$, (b) $\mathrm{H}_{2} \mathrm{SO}_{4}+[\mathrm{CuL}]^{2+}$, (c) $\mathrm{H}_{2} \mathrm{SO}_{4}+$ malic acid. The results indicate that only $\mathrm{BrO}_{3}{ }^{-}$can react with paracetamol, as is shown in (Fig. 4).

Paracetamol contains an active hydroxyl, which could be easily oxidized to corresponding substitute in oscillating system. From the result of cyclic voltammetry, $\mathrm{BrO}_{3}{ }^{-}$ is the most possible matter that can react with paracetamol. The reaction is as follows:<smiles>CC(=O)Nc1ccc(O)cc1</smiles>

In reaction (8), when a large amount of $\mathrm{BrO}_{3}{ }^{-}$is consumed, reactions (1), (2), (3), and (5) are restrained to some extent, making the concentration of $\mathrm{BrO}_{2} \cdot$ decrease accordingly reaction (5). With the decrease of free $\mathrm{BrO}_{2}$. concentration, the concentration of $[\mathrm{CuL}]^{3+}$ in the system decreases and that of $[\mathrm{CuL}]^{2+}$ increases, so the value of $\ln \left([\mathrm{CuL}]^{3+} /[\mathrm{CuL}]^{2+}\right)$ decreases sharply and the potentiometric oscillations are seen to decrease (Fig. 1b). 
Because the concentration of paracetamol was relatively low in oscillating system, the system recovered rapidly to initial oscillating state after exhausting the paracetamol.

Clarifying the exact mechanism of the paracetamol perturbation of this oscillating system is still problematic, because of the lack certain relevant data. However, our research is in progress.

\section{Conclusions}

The oscillation amplitude of $\mathrm{NaBrO}_{3}-\mathrm{H}_{2} \mathrm{SO}_{4}$-malic acid-[CuL] $\left(\mathrm{ClO}_{4}\right)_{2}$ system increased sharply when paracetamol was added into the oscillating system. The changes in oscillation amplitude are linearly proportional to the logarithm of the concentration of paracetamol. The optimum conditions for analysis of paracetamol were as follows: $1 \mathrm{M} \mathrm{H}_{2} \mathrm{SO}_{4}$ solution, $0.01875 \mathrm{M} \mathrm{NaBrO}_{3}$ solution, $0.20 \mathrm{M}$ malic acid and $3.04 \times 10^{-3} \mathrm{M}[\mathrm{CuL}]\left(\mathrm{ClO}_{4}\right)_{2}$ solution. The analytical curve for paracetamol was in the concentration range from $5 \times 10^{-7}$ to $2 \times 10^{-4}$ M. In this way, the kinetic analytical method of paracetamol has been established, and this method is simple, rapid and sensitive. The cyclic voltammetry experiments have shown that paracetamol is oxidized by $\mathrm{BrO}_{3}{ }^{-}$during its perturbation on the oscillating system.

\section{Acknowledgment}

The authors gratefully acknowledge funding of this work by the National Science Foundation of China (21171002).

\section{References}

1. Field R J, and Schneider F W, J Chem Educ., 1989, 66(3), 195-204.

2. Tichonova L P, Zakrevskaya L N and Yatsimirskii K B, J Anal Chem., 1978, 33, 1991.

3. Hu G, Zhao F S, Lu M Y, Zhu L, Guo M M, Liu H Y and Hu L, Helv Chim Acta, 2011, 94(5), 903-913.

4. Furrow S D, Cervellati R and Amadori G, J Phys Chem. A, 2002, 106(24), 5841-5850.

5. Furrow S D, J Phys Chem., 1981, 85(14), 2026-2031.

6. Furrow S D and Noyes R M, J Am Chem Soc., 1982, 104(1), 38-42.

7. Bray W C, J Am Chem Soc., 1921, 43(6), 1262-1267.

8. Bray W C and Liebhafsky H A, J Am Chem Soc., 1931, 53(1), 38-44.

9. Kolar-Anić L and Schmitz G, J Chem Soc., Faraday Trans., 1992, 88(16), 2343-2349.

10. Kolar-Anić L, Cupic Z, Anic S and Schmitz G, J Chem Soc., Faraday Trans., 1997, 93(12), 2147-2152.

11. Schmitz G, Phys Chem Chem Phys., 2011, 13(15), 7102-7111.

12. Schmitz G, Phys Chem Chem Phys., 2010, 12(25), 6605-6615.

13. Gao J Z, Yang H, Liu X H, Ren J, Li Q Z and Kang J W, Talanta, 2002, 57(1), 105-114.

14. Luo Y, Orban M, Kustin K and Epstein I R, J Am Chem Soc.,1989, 111(13), 4541-4548.

15. Jiménez-Prieto R, Silva M and Pérez-Bendito D, Anal Chim Acta, 1996, 334(3), 323-330.

16. Pejic N D, Blagojevic S M, Anic S R, Vukojevic V B, Mijatovic M D, Ciric J S, Markovic Z S, Markovic S D and Kolar-Anic L Z, Anal Chim Acta, 2007, 582(2), 367-374.

17. Field R J and Burger M, Oscillations and travelling waves in chemical system. Wiley, New York, 1985.

18. Xu C L and Li B X, Spectrochim Acta, part A, 2004, 60(8-9), 1861-1864.

19. Vilchez J L, Blanc R, Avidad R and Navalon A, J Pharm Biomed Anal., 1995, 13(9), $1119--1125$.

20. Shockcor J P, Unger S E, Wilson I D, Foxall P J D, Nicholson J K and Lindon J C, Anal Chem., 1996, 68(24), 4431-4435. 
21. Tanaka H, Dasgupta P K and Huang J, Anal Chem., 2000, 72(19), 4713-4720.

22. Goicoechea A G, López De Alda M J and Vila-Jato J L, J Liq Chromatogr., 1995,18(16), 32573268.

23. Bari V, Dhorda U J and Sundaresan M, Indian Drugs, 1998, 35(4), 222-225.

24. Easwaramoorthy D, Yu Y and Huang H, Anal Chim Acta, 2001, 439(1), 95-100.

25. Murray S and Boobis A R, J Chromatogr B, 1991, 568(2), 341-355.

26. Afshari J T, andTsan-Zon L, Anal Chim Acta, 2001, 443(1), 165-169.

27. Šatinský D, Neto I, Solich P, Sklenářová H, Conceicăo M, Montenegro B S M and Araújo A N, J Sep Sci., 2004, 27(7-8), 529-536.

28. Heitmeier S and Blaschke G, J Chromatogr B, 1999, 721(1), 93-108.

29. Rodenas V, García M S, Sánchez-Pedreño C and Albero M I, Talanta, 2000, 52(3), 517-523.

30. Hu G, Chen P P and Wang W, Electrochem Acta, 2007, 52(28), 7996-8002.

31. Chen P P, Hu G and Wang W, J Appl Electrochem., 2008, 38(12), 1779-1783.

32. Hu G, Chen L L, Zhang J F, Chen P P, Wang W, Song J M, Qiu L G, Song J, and Hu L, Cent Eur J Chem., 2009, 7(3), 291-297.

33. Chen L L, Hu G, Zhang J F and Hu L, Mendeleev Commun., 2009, 19(4), 224-226.

34. Jimēnez-Prieto R, Silva M, and Perez-Bendito D, Analyst, 1997, 122(3), 287-292.

35. House D A and Curtis N F, J Am Chem Soc., 1964, 86(2), 223-225.

36. Field R J, Körös E and Noyes R M, J Am Chem Soc., 1972, 94(25), 8649-8664.

37. Hu G, Zhang Z D, Hu L, and Song J M, Transition Met Chem., 2005, 30(7), 856-860. 


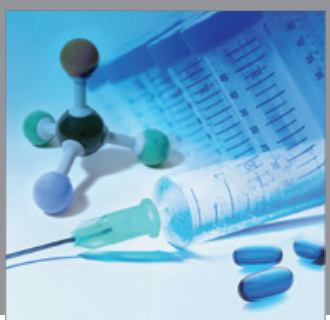

International Journal of

Medicinal Chemistry

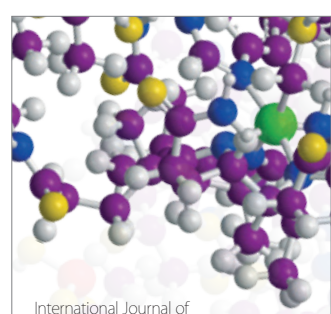

Carbohydrate Chemistry

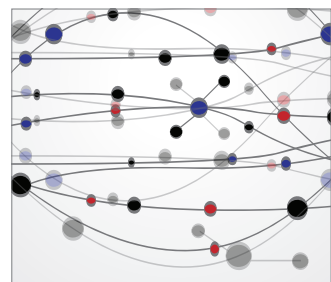

The Scientific World Journal
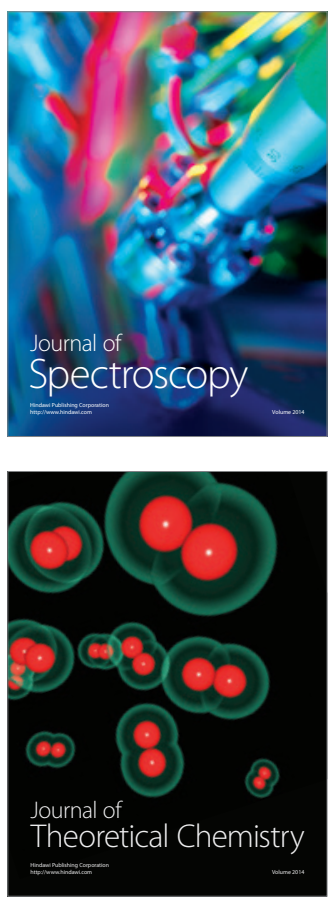
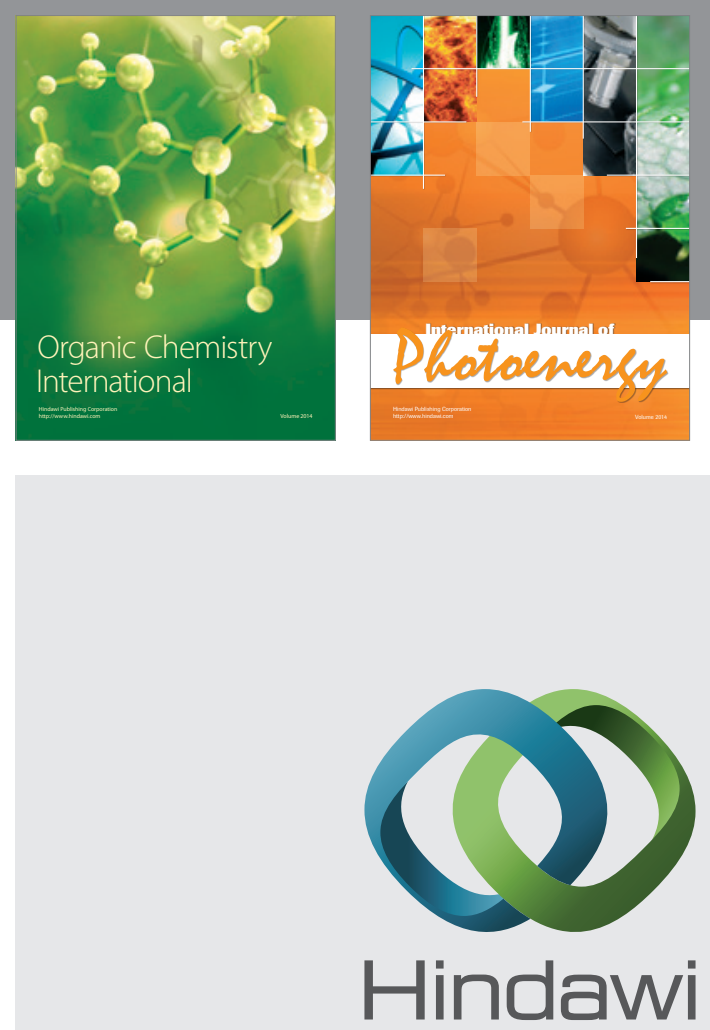

Submit your manuscripts at

http://www.hindawi.com
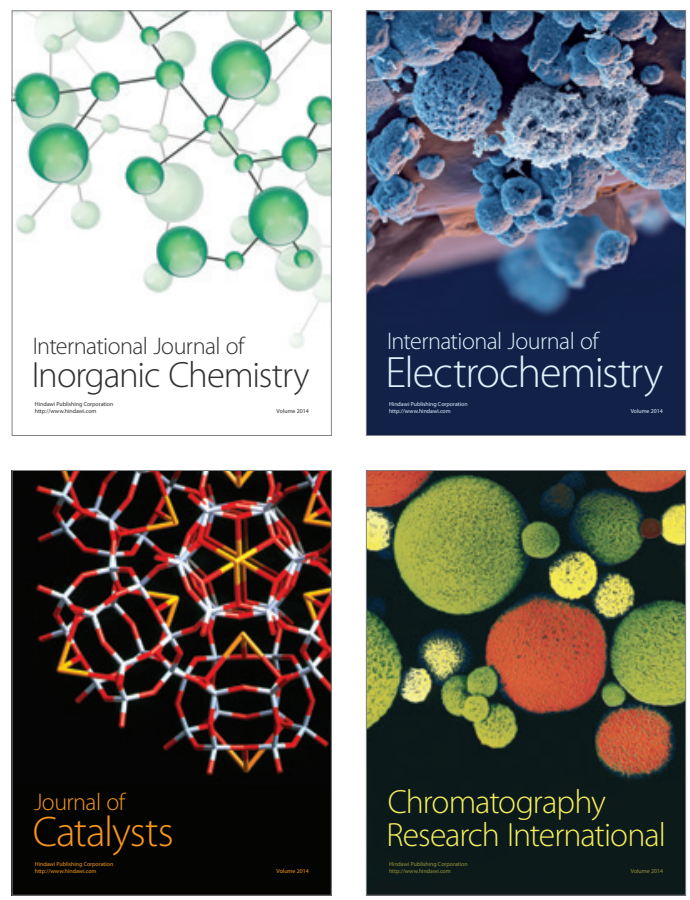
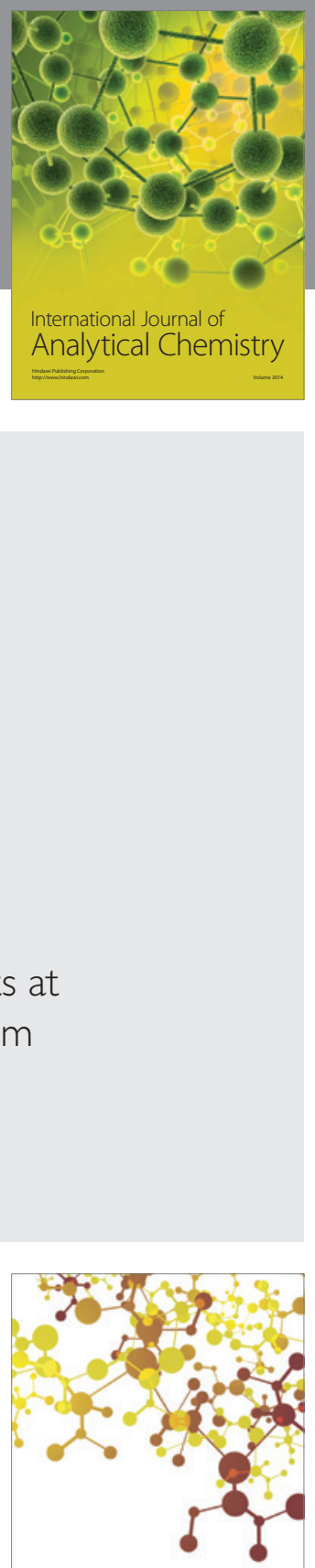

Journal of

Applied Chemistry
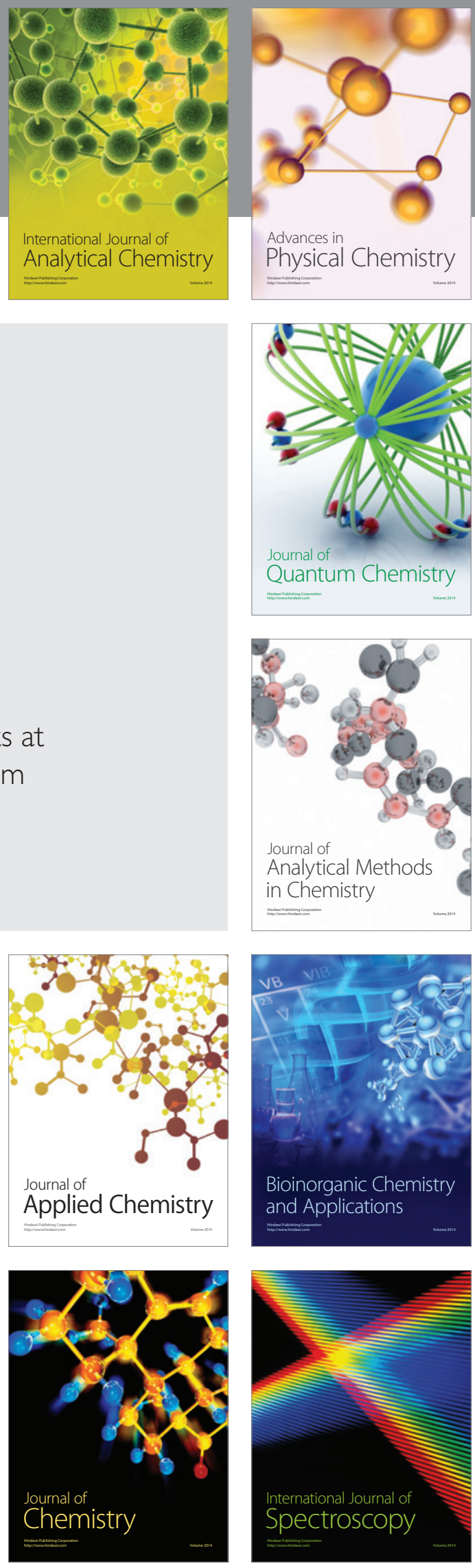